Int. J. Electrochem. Sci., 14 (2019) 7703 - 7716

\title{
Facile Synthesis of Fe-MOF/rGO nanocomposite as an Efficient Electrocatalyst for Nonenzymatic $\mathrm{H}_{2} \mathrm{O}_{2}$ Sensing
}

\author{
Suling Yang ${ }^{1,2, *}$, Mengyu $\mathrm{Li}^{1,2}$, Ziling Guo ${ }^{1,2}$, Ning Xia ${ }^{1,2, *}$, Lingbo $Q u^{1,3}$ \\ ${ }^{1}$ College of Chemistry and Chemical Engineering, Anyang Normal University, Anyang 455002, PR \\ China \\ ${ }^{2}$ Henan Key Laboratory of New Opto-electronic Functional Materials \\ ${ }^{3}$ College of Chemistry and Molecular Engineering, Zhengzhou University, Zhengzhou 450001, PR \\ China \\ *E-mail: yang_suling@163.com; xianing82414@163.com
}

doi: $10.20964 / 2019.08 .42$

Received: 17 March 2019 / Accepted: 15 May 2019 / Published: 30 June 2019

\begin{abstract}
An Fe-MOF (metal-organic framework)/reduce graphene oxide (rGO) nanocomposite was formed by using an efficient synthetic method. The morphology and structure of the Fe-MOF/rGO nanocomposite were characterized by scanning electron spectroscopy (SEM) and X-ray diffraction (XRD). The Fe$\mathrm{MOF} / \mathrm{rGO}$ nanocomposites were immobilized on a carbon paste electrode (CPE) to construct a highperformance nonenzymatic electrochemical $\mathrm{H}_{2} \mathrm{O}_{2}$ sensor. A cyclic voltammetry (CV) study showed that the $\mathrm{Fe}-\mathrm{MOF} / \mathrm{rGO}$ nanocomposites displayed better electrocatalytic activity toward $\mathrm{H}_{2} \mathrm{O}_{2}$ reduction compared to that of Fe-MOF. An amperometric study indicated that the $\mathrm{H}_{2} \mathrm{O}_{2}$ sensor displayed high performance, which offered a low detection limit $(0.5 \mu \mathrm{M})$, a high sensitivity $\left(5.17 \mu \mathrm{A} \mathrm{mM}^{-1} \mathrm{~cm}^{-2}\right)$, and a wide linear range (from 5.0 to $945 \mu \mathrm{M}$ ). An electrochemical reaction mechanism was proposed for $\mathrm{H}_{2} \mathrm{O}_{2}$ reduction on the $\mathrm{Fe}-\mathrm{MOF} / \mathrm{rGO} / \mathrm{CPE}$. Importantly, the as-fabricated $\mathrm{H}_{2} \mathrm{O}_{2}$ sensor exhibited good reproducibility and excellent selectivity. Furthermore, the constructed high-performance sensor was utilized to monitor the $\mathrm{H}_{2} \mathrm{O}_{2}$ levels in real samples, and satisfactory results were obtained. These results demonstrated that the $\mathrm{Fe}-\mathrm{MOF} / \mathrm{rGO}$ nanocomposite can be used as a good electrochemical sensor material in practical applications.
\end{abstract}

Keywords: Metal organic framework, $\mathrm{Fe}-\mathrm{MOF} / \mathrm{rGO}$ nanocomposite, electrocatalytic activity, $\mathrm{H}_{2} \mathrm{O}_{2}$.

\section{FULL TEXT}

(C) 2019 The Authors. Published by ESG (www.electrochemsci.org). This article is an open access article distributed under the terms and conditions of the Creative Commons Attribution license (http://creativecommons.org/licenses/by/4.0/). 